\title{
Der Landesverband Thüringen setzt auf Studentenarbeit
}

\begin{abstract}
Es ist allgemein bekannt, dass ein demografischer Wandel bevorsteht. Um dem entgegenzuwirken, engagiert sich der FVDZ-Landesverband Thüringen schon seit Jahren in der Studentenarbeit an der Friedrich Schiller Universität Jena (FSU).
\end{abstract}

Seit 2012 ist Dr. Elisabeth Triebel Vorstandsmitglied des FVDZ in Thüringen und verantwortlich für die Studentenbetreuung. Ihre Aufgabe ist es, die nachrückenden Zahnmediziner für die Standespolitik zu interessieren. Kontakte zur Fachschaft Zahnmedizin der FSU hat Triebel schnell geknüpft und das Interesse der Studenten an FVDZ-Angeboten geweckt. Dies betrifft unter anderem MEDI-LEARN als Internetplattform zur Vorbereitung auf Prüfungen oder die Unterstützung bei Auslandsaufenthalten über den Zahnärztlichen Austauschdienst (ZAD). Auf Anregung der Studenten bietet der FVDZ Thüringen in Kooperation mit der Deutschen Ärzte Finanz (DÄF) auch seit 2012 verschiedene Kurse als Unterstützung an, wie zum Beispiel einen Notfallkurs und einen Naht- und Knotenkurs.

\section{Run auf begehrte Kurse}

Mittlerweile hat schon der 4. Notfallkurs erfolgreich stattgefunden, wie immer mit den Rettungsärzten Barbara SpohnKöniger und Dr. Heribert Köhniger aus Mittenwald. Der Vorteil bei diesen Notfallkursen: Die Eheleute Königer sind selbst als Rettungsärzte aktiv, und Heribert Königer ist sowohl Arzt als auch Zahnarzt. Er kann entsprechende Tipps geben, wie man reagieren soll und muss, wenn ein Notfall auf dem Behandlungsstuhl im Studentenkurs oder auch später in der Praxis auftreten sollte. Beide Mediziner stellen in anschaulichen Bildern und praktischen Übungen dar, worauf zu achten ist. Die Plätze in den Notfallkursen sind immer schnell besetzt und werden oft angefragt.

Der begehrte Naht- und Knotenkurs ist Ende vergangenen Jahres ebenfalls im 4. Durchlauf erfolgreich durchgeführt worden. Triebel selbst und Dr. Alexander Volkmann versuchen, ehrenamtlich das instrumentelle und das manuelle Nähen sowie Knüpfen bei chirurgischen Arbeiten darzustellen. In den eineinhalb bis zwei Stunden sind die Studenten hochkonzentriert dabei, stellen viele Fragen und bearbeiten die Schweineohren mit Skalpell, Nadel und Faden.

Auf diese Weise veranschaulichen die erfahrenen Zahnärzte den Studenten, warum es wichtig ist, sich ehrenamtlich in der Standespolitik einzubringen. Vielleicht nicht jetzt sofort, aber eventuell etwas später. Zumindest ist das Interesse geweckt.

Landesverband Thüringen
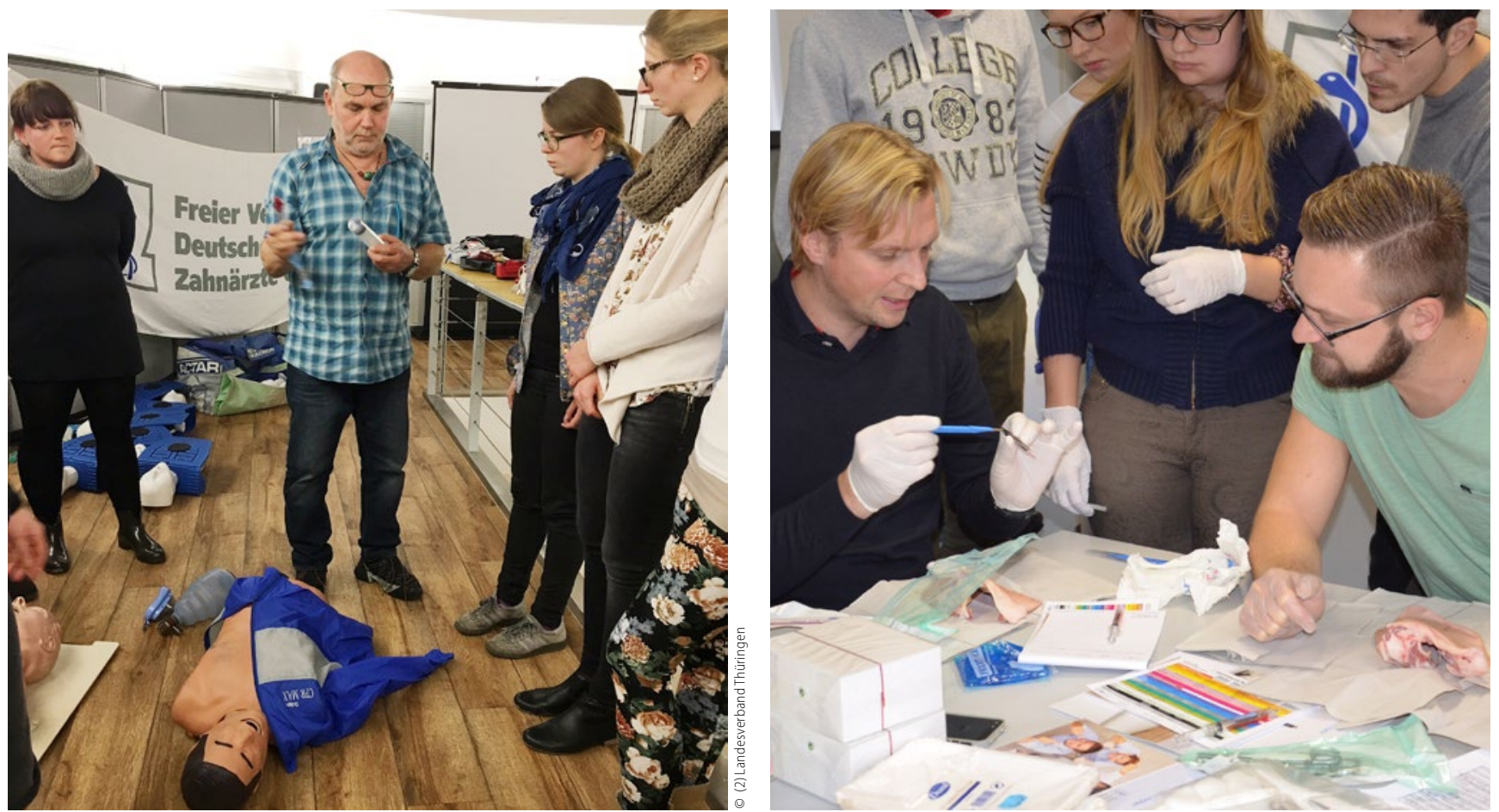